\title{
A Study of Trump's Inaugural Speech and Its Chinese Version from the Perspective of Transitivity
}

\author{
Donghui Wang ${ }^{1} \&$ Liangqiu Lyu ${ }^{1}$ \\ ${ }^{1}$ School of Foreign Languages, North China Electric Power University, Beijing, China \\ Correspondence: Donghui Wang, School of Foreign Languages, North China Electric Power University, Beijing, \\ China. E-mail: 674790016@qq.com
}

Received: September 27, 2018 Accepted: October 24, 2018 Online Published: December 29, 2018

doi:10.5539/ijel.v9n1p185 URL: https://doi.org/10.5539/ijel.v9n1p185

This paper is supported by the NCEPU "Double First-Class" Graduate Talent Cultivation Program, No. XM1805222.

\begin{abstract}
In linguistics, Systemic Functional Linguistic School represented by Halliday has been having a great impact in the field of discourse analysis in the past 30 years and has become one of the important discourse analysis schools. As a significant part, transitivity reflects the ideational function in the systemic functional grammar and boasts a wide application in discourse analysis, such as in speeches. This paper has selected Trump's inaugural speech and its Chinese version as a case study for sample and quantitative analysis of underlying textual features of political speeches from the perspective of Halliday's transitivity, attempting to help readers get a better understanding of transitivity theory and features of political speeches, as well as consequently master the method of applying transitivity to political speeches. Furthermore, by way of a contrastive analysis of transitivity between Trump's inaugural speech and its Chinese translation, it tries to delve into the translation strategies of political speeches, to guide practice translation of political speeches, to prove the applicability of transitivity in translation studies and to offer a creative angle for further researches.
\end{abstract}

Keywords: transitivity, process, Trump's inaugural speech, translation

\section{Introduction}

Experiential function is a part of Halliday's systemic functional grammar, which refers to the function of the speaker as an observer to express one's social experience and internal psychological experience. Among various semantic systems in the experience function, the transitivity is the most important. Transitivity can highlight the location of things and identify the type of sentence (Jiang, 2013). It is the transitivity that divides the human experience towards the entire world into several processes and figures out the participants and factors. With the advent of globalization, socialization and information revolution, the competition is dramatically increasing, as well as the society's selection criteria for talents are increasingly integrated. As an example, in western countries, an important way of becoming leaders is by giving speech to advocate the speakers' plans and to gain the supporters. According to the content of speech, it can be divided into mainly five types, that is to say, political speech, academic speech, life speech, court speech and religious speech (Shao, 1991). Political speeches refer to speeches given by government officers, by which they aim to indicate their position on the state's internal affairs and foreign relations, to publicize their positions, and to clarify their views. Leaders' victory speeches, inaugural speeches, and governance speeches all belong to political speeches, which play a vital role in the political interaction among countries ( $\mathrm{Li}, 2003)$.

Trump became the fourth businessman in the history of the United States and was officially sworn in Washington, D.C., and delivered his inaugural speech. Within 17 minutes, he pointed out the defects of the previous American politics and described his own governance policy and political vision. Moreover, Trump's inaugural speech has gained a mounting number of Chinese's attention. Therefore, its Chinese version also deserves pouring attention to. However, the majority of the previous studies are from the perspective of stylistics (Huang, 2017), critical discourse analysis (Zhang \& Zhou, 2018) or interpersonal function (Xu, 2017). Few studies have analyzed this inaugural speech from the perspective of transitivity, let alone analyzing its translated version. Zhang (2010) put 
forward that "formal equivalence" can be employed as a standard to measure the suitability of translations. Analyzing Trump's inaugural speech and its Chinese version from the point of transitivity view can help the readers to know better about the characteristics of political speeches and to guide readers in analyzing the texts with Halliday's theory, as well as to try to explore translation methods of political speech.

\section{Overview of Transitivity}

The system of transitivity is a semantic system in which the conceptual function is expressed in the system functional grammar, and the basic unit of the language is the clause. There are six main processes: material processes, mental process, relational process, behavioral process, verbal process and existential process (Hu et al., 2017).

\subsection{Definition of Transitivity}

Halliday, who was the founder of system-functional linguistics, holds the view that a great variety of cultures can reflect a certain degree of universal concepts in regard to language, which is called metafunction, including ideational metafunction, interpersonal metafunction and textual metafunction. Ideational metafunction refers to the direct reflection of language on the process, stage and relationship of affairs in the objective world. Afterwards, Thompson divides Halliday's ideational metafunction into experiential function and logical function (Thompson, 2008). The experiential function means the expression of language towards diverse experience of humanity both from the factual world and the inner world. In other words, it reflects the things happen in the objective and subjective world, as well as the relative time, location, individuals and other environmental factors are involved. Halliday pointed out that the definition of transitivity system is termed by the paradigmatic and syntagmatic relations of clauses (Halliday, 2008). Transitivity is a grammatical system which turns the world of experience into a manageable set of process types.

\subsection{Processes in Transitivity}

As for the classification of transitivity, there are two kinds of types, namely, process emphasizing motion and process emphasizing state. As for the first classification of transitivity, material process, mental process, verbal process and behavior process belong to it. In terms of the second type of transitivity, relational process and existential process belong to it.

The Material processes are those in which something is done or are those involving physical actions, such as beating, breaking, kicking, running, throwing, sitting and so on. Since describing the outer experience of human, it emphasizes the motion. One of the participants is called "Actor", which is the doer of the action. Another participant is called "Goal" which is the receiver of the action. Mental processes are processes that depict the thoughts, preferences, desire and feelings of interior worlds in people's minds. In general, it consists of two participants: Senser and Phenomenon. Senser refers to persons and animals which produce the mental change. At the same time, the "Phenomenon" is that which is "sensed". Verbal processes refer to the processes of exchanging information by "saying". The participants of verbal processes are Sayer, Receiver or Target and Verbiage. Sayer means the speaker of an action, and Receiver refers to the part which receiver the message carried out by the Sayer. Verbiage means the certain information that needs to be conveyed to Receiver or a thing that Receiver needs to do. Some verbs belong to verbal processes, such as "say, talk, praise, tell, describe". Behavioral processes refer to the mental and physical behaviors, which it is mainly identified by the meaning of a clause. Behavioral processes usually have only one participant that is Behavior.

Relational process and existential process emphasize state in transitivity system. The Relational processes refer to the processes which reflect the relationship that is being set up between two separate entities. There are two types, including attributive and identifying. Attributive relational process means one entity has some quality ascribed or attributed to it. Two participants of this kind of Relational processes are Carrier and Attribute. In contrast, the function of identifying relational process is to identify one entity in terms of another. The two participants are Token and Value. The existential process is the process of the existence of something. The participant of the process of existence is "existential", which often appears in the clause of existence process, does not express any conceptual function, but only serves as a guide to these clauses. Existential processes indicate the existence of an entity, of which the typical symbol is "there" as the subject of a clause. What's more, there is only one participant: Existent.

These processes generalize the most important activities and events in human experience world. On the whole, in a discourse, a certain number of processes, especially a certain number of the same type of processes, or a certain number of two types of processes with a certain degree of correlation, are frequently intertwined, resulting in an effect of "foregrounding." Thus, when the transitivity system is used to analyze texts, it is necessary to mainly 
understand the application or distribution patterns of various processes in the text, that is, which type of process is the most prominent, then the next, and which type is the least, then explain this to find out or reveal the speaker's motivation to do this "expressing choice", so as to discover the deep empirical significance of the text.

\section{Analysis of Transitivity in Trump's Inaugural Speech and Its Chinese Version}

Trump, as the 58th President of the United States, his inaugural speech is an extremely influential political speech with distinctive language features. In the speech, the speaker will skillfully use speech techniques to achieve the purpose of his speech (Graber, 2003). Thus, it is the same with Trump's inaugural speech. Transitivity is a semantic system that can classify people's experience in the real world and inner world into "processes" through transitivity analysis. In addition, transitivity analysis can categorize experience by grammar, and specify "participants" and "environmental elements" related to various processes. Thus, what this thesis is concerned is studying transitivity by using Trump's inaugural speech and its translated version as a case study to explore effective translation methods and better understanding of functional grammar.

This thesis chooses Trump's inaugural speech and its Chinese translation from Voice of America as corpus. According to the characters of each process, the authors analyze the corpus sentence by sentence under the guideline of inductive method. The followings are the analysis results. There are a sum of 98 clauses in the selected Trump speeches, of which material processes (47 times, $48 \%$ of the total process) and relational processes ( 28 times, $22.11 \%$ of the total) emerge most. In addition, the mental process occurred 17 times, accounting for $17.2 \%$ of the total number of processes, and the behavioral process does not appear. The verbal process and the existential process have only appeared twice and four times respectively, accounting for $2 \%$ and $4.1 \%$ of the total number of processes. The results are presented in tabular form as follows:

Table 1.2017 Trump presidential inaugural speech distribution process statistics

\begin{tabular}{lllllll}
\hline Process & Material & Mental & Verbal & Behavioral & Relational & Existential \\
\hline Number(98) & 47 & 17 & 2 & 0 & 28 & 4 \\
Percent & $48 \%$ & $17.2 \%$ & $2 \%$ & $0 \%$ & $28.6 \%$ & $4.1 \%$ \\
\hline
\end{tabular}

Transitivity not only describes the relationship between verbs and objects, but also describes the relationship of elements in the entire sentence. Therefore, to make a transitory analysis of a clause, it is necessary to understand these three aspects. Firstly, what kind of process it belongs to? Secondly, how many participants are in the process? Thirdly, what is the role of every participant?

\subsection{Process Emphasizing Motion}

Processes are the cores of the clause from the experiential perspective: the clause is primarily "about" the event or state that the participants are involved in. The process is typically expressed or realized by the verbal group in the clause. In some cases, the process can be seen as including another constitution apart from the verbal group proper. Four processes belong to it, including material process, mental process, behavior process and verbal process.

\subsubsection{Material Process}

In material process, the verb is very important for that material process is a process of "doing", and it should be carried out by the verb. At the same time, Actor and Goal, as the participants of the material process can clearly indicate the source and the object of the action, and also reveal the status of the participants. It has certain significance and the translation needs to be performed accordingly. As can be seen from the Table 1, the number of sentences in the material process of Trump's inaugural speech is relatively large, and the proportion in the entire space is relatively large. The sentence of the material process expresses the objective facts, and has authenticity and objectivity, which provides the listener with more confidence in the content of the speech, as well as the subject of the inaugural speech is expressed more objectively and truthfully with the employing the material process. The following is an analysis of the clause and translation of the material process in Trump's inaugural speech:

\section{Example 1:}

ST (source text): Together, we will determine the course of America, and the world, for many, many years to come.

TT (target text): 我们将一起决定美国和世界今后许多年的走向。 
The source text belongs to the material process, which is shown through the verb "determine". The Actor of this clause is "we", because the speaker wants to form an intimate relationship with the audience. On the one hand, it is clearly to see that the plural form "we" seems closer than singular form "I"; on the other hand, "we" can also be regarded as the American common citizens. Thus, the using of "we" as the Actor is very suitable. The Goal of this clause is "the course of America and the world". "Together, for many, many years to come" can be seen as circumstantial factors, as discussed above, which can be omitted in many contexts, but here it emphasizes that the time is quiet long. Therefore, the whole clause gives the audience the encouragement that Trump's determination of being together with Americans throughout the difficulties in the long run. The translation of this clause belongs to the material process, too. “决定” is the typical verb of material process, and the Actor “我们” is equal to “we” in the source text. The Goal “美国和世界今后许多年的走向” is also the same with the source text.

When translated into Chinese, the clause still belongs to material process since the elements, like Actor, Goal and verb are not changed, although some circumstantial factors are changed the order. The employing of free translation strategy fills the gap between Chinese and American cultural thinking modes, which conveys the meaning of the source text successfully.

\section{Example 2:}

ST: We will be protected by the great men and women of our military and law enforcement and, most importantly, we will be protected by God.

\section{TT: 我们将受到军队和执法部门伟大的男男女女的保护，最重要的是，受到上帝的保护。}

The source text is a kind of material process. The position of Actor and Goal is changed, since it is a passive voice. Therefore, "we" is the Goal in the material process and "the great men and women of our military and law enforcement" are the Actor. Placing "we" in the first position is to emphasize the unity of the American people. The verb "protect" expresses that it is safe to live in the United States due to a perfect legal system and army and they are protected by God. The subject of the sentence is the first person, which can make the speaker's language more authentic and amicable. It can narrow the distance with the listener and make the listener occupy the side that is beneficial to him and make the speech smoother. The target text also belongs to the material process, which consists with the source text. “将受到...保护” is equal to the source text "protect" in the structure, and the semantic meaning is also the same with the source text.

Example 3:

ST: So to all Americans, in every city near and far, small and large, from mountain to mountain, and from ocean to ocean, hear these words:

\section{TT: 所有美国人，不管城市的大小和远近，在两洋之内，在大山之间，都请记住下面的话:}

This clause belongs to the material process since it uses the objective verb "hear" to express. Actor is carried out by "all Americans" and "these words" is the role of Goal. As for " in every city near and far, small and large, from mountain to mountain, and from ocean to ocean," even though it seems to complex, it just serves as circumstance since it indicates the degree of distance. In this clause, the speaker employs the material process to inspire the audience, which is full of authentic and persuasive favors. The semantic meaning of the translation remains the same with the source text, while it changes from the material process clause into a mental one during translation. “记住” is a symbol verb of mental process, while the source text is "hear". When translating, the circumstance and target culture should be taken into consideration. Changing the material process into mental process meets the language expression habits of Chinese.

Table 2. Material process analysis

\begin{tabular}{|c|c|c|c|c|c|}
\hline Participant & Circumstance & Actor & Process: Material & Goal & Circumstance \\
\hline ST 1 & together & we & will determine & $\begin{array}{l}\text { the course of America, } \\
\text { and the world }\end{array}$ & $\begin{array}{l}\text { for many, many } \\
\text { years to come }\end{array}$ \\
\hline ST 2 & & $\begin{array}{l}\text { the great men and women } \\
\text { of our military and law } \\
\text { enforcement; God }\end{array}$ & will be protected & we & $\begin{array}{l}\text { most } \\
\text { importantly }\end{array}$ \\
\hline ST 3 & $\begin{array}{l}\text { in every city near and } \\
\text { far, small and large, } \\
\text { from mountain to } \\
\text { mountain, and from } \\
\text { ocean to ocean }\end{array}$ & all Americans & Hear & these words & \\
\hline
\end{tabular}


The analyzed examples can be shown in the Table 2 above. Trump tends to use the first-person material process to present objective facts, which makes the speech more intimate and realistic, and it can add charm to the speech and make the audience more believe his words. The sentences of these material processes all express distinct political opinions and objective facts, which make the audience more confident in the speaker's speech and more inclined to his position. This plays an important role. In Trump's speech, the proportion of sentences in the material process is relatively large. It can be seen that Trump's speech contains objective historical facts as well as his own thoughts and opinions. Besides, his speech is very logical and methodical.

\subsubsection{Mental Process}

In Trump's speech, there are 17 phrases in the mental process, accounting for $17.2 \%$ of the entire speech. These mental process clauses play an important role in the entire discourse, expressing Trump's subjective will and making the speech more vivid. The mental process generally has two participants, one is the Senser and the other is the Phenomenon. In Trump's speech, the Sensers of mental process clauses are generally humans, and most of them are first-person. From the following example analysis, we can explore the characteristics of Trump's mental process clause, the function of the sentence and the translation strategies.

Example 4:

ST: Every four years, we gather on these steps to carry out the orderly and peaceful transfer of power, and we are grateful to President Obama and First Lady Michelle Obama for their gracious aid throughout this transition.

They have been magnificent.

$\mathrm{TT}$ : 每隔四年, 我们都聚集在这些台阶上, 进行有序而和平的权力交接。我们感谢奥巴马总统和第一夫 人米歇尔·奥巴马在这一过渡过程中给予的慷慨帮助。他们很了不起。

The Senser of this mental process is "we", and the using of the first person as the subject to show that Trump himself is as grateful as all Americans. The original object of gratitude is "President Obama and First Lady Michelle Obama". The structure "are grateful" shows their respect of Obama and his wife. This sentence uses a mental process to express his gratitude to the former president and to thank Obama for his contribution to the country. This also reflects Trump's humility, and such behavior has left a good impression on the audience. Accordingly, Chinese translation is a sentence of mental process, too. Senser is “我们”, “感谢” is Trump's expression of his inner feelings, which belongs to the metal process. Moreover, the translation of the environmental components is also corresponding with the source text. The emotional expression is also consistent with the source text.

\section{Example 5:}

ST: Americans want great schools for their children, safe neighborhoods for their families, and good jobs for themselves.

\section{TT: 美国人希望孩子有个好学校, 家庭有个好社区, 自己有个好工作。}

This clause is a typical mental process, with "Americans" as Senser and "great schools, safe neighborhoods, good jobs" as Phenomenon. The verb "want" express the will of Americans, for their aims of having great schools for their children, safe neighborhoods for their families, and good jobs for themselves. In the translation, it changed into “希望。oo。 有” as the main verb, which carries the general meaning of clause. Because the source text tends to express the details of their hopes, the Chinese version tends to focuse on the objective sense, which is more suitable to translate into material process instead of mental process. This example tells us a new aspect of translation strategy, that is, especially in political speech translation, the transitivity of the source text can be changed for the purpose of transport the whole function of the source text to the target text.

Table 3. Mental process analysis

\begin{tabular}{llll}
\hline Participant & Senser & Process: Mental & Phenomenon \\
\hline ST 1 & we & are grateful to & President Obama and First Lady Michelle Obama \\
ST 2 & Americans & want & great schools, safe neighborhoods and good jobs \\
\hline
\end{tabular}

After the translation of the phrase of mental process in Trump's speech, some clauses do not change from the perspective of transitivity system. Thus, the translation is consistent with the original text. However, some mental process clauses have changed into material process during translation, because the emphasis in English texts is on the verbs of the material process behind the mental process. Therefore, after translation, the important function of the original text must be shown. 


\subsubsection{Verbal Process}

Usually, the speaker uses the verbal process when quoting other people's words. There are direct quotes and indirect quotes. Since the speech mainly expresses the speaker's own opinions and political views, the excessive use of others' words may make people feel that the speech is empty and there is no real content. However, sometimes citations of famous celebrities will make the speech more persuasive and enhance the momentum of the speech. There are two clauses in the verbal process in Trump's speech, accounting for $2 \%$ of the entire speech. He uses such process to support his own statement, which plays a very positive role.

Example 6:

ST: The Bible tells us: "How good and pleasant it is when God's people live together in unity."

TT: 《圣经》告诉我们, “上帝的子民和睦共处是多么美好愉快的事情。”

This sentence is a typical verbal process clause, because the speaker quotes the words from the Bible, which is the most important book in western countries. By employing the sentence from the authoritative book, Trump tries to make his speech credible. "The Bible" is the Sayer, and "us" is the Receiver. "How good and pleasant it is when God's people live together in unity." is the Verbiage in the verbal process. The verb "tell" is the symbol word of verbal process. As for the translation, "我们" is equal to "us" in the source text, and both of them play the role as object. “《圣经》" is consists with "the Bible", since it is the proper noun, which should be translated literally. From above, we can see that when the source text belongs to the verbal process clause and it quotes others' words, the literal translation strategy can be employed and remain its transitivity.

\section{Example 7:}

ST: Do not allow anyone to tell you that it can not be done.

$\mathrm{TT}$ : 不要让任何人对你说这是做不到的。

The source text is a verbal process. The Sayer is "anyone" and "tell" is the verb in the verbal process and the elements after the word "that" is the verbiage, which contains the content of the Sayer. The translation version also belongs to the verbal process, with the obvious verb "说" . It is safe to draw a conclusion that the verbal process remains the same when translated into the target text, since it still followed the Sayer.

Table 4. Verbal process analysis

\begin{tabular}{lllll}
\hline Participant & Sayer & Process: Verbal & Receiver & Verbiage \\
\hline ST 1 & the Bible & tells & us & $\begin{array}{l}\text { How good and pleasant it is when God's people } \\
\text { live together in unity } \\
\text { ST 2 }\end{array}$ \\
anyone & tell & you & that it cannot be done \\
\hline
\end{tabular}

In Trump's inaugural speech, the transitivity of clauses of the verbal process is not changed after the translation because the verbs in the English verbal process are consistent with the words in Chinese. Therefore, the original language must remain transitive after translation. Since the verbal process expresses objective facts, during the translation, it is suitable to employ the literal translation strategy according to the original content.

\subsubsection{Behavior Process}

Behavioral process refers to the process of physical activity such as breathing, coughing, sighing, dreaming, crying, etc., which is between the material process and the mental process, and distinguishing the pure mental process from the external physical features it exhibits. On the one hand, the participants generally have only one Actor, and they are generally human; on the other hand, the rest is circumstance. In Trump's inaugural speech, there is no sentence of behavioral process, mainly because the speech language is always expressing a certain purpose, representing a material process of objective facts, and expressing mental process clauses of inner feelings.

There are relational processes to express the characteristics and relationships between things and the verbal processes to recounting others' words, but there are no behavioral sentences in the speeches. It is caused by the features of speech that it needs more objectivity and seriousness. The behavioral process generally occurs in fiction or colloquial language to describe an event.

\subsection{Process Emphasizing State}

As well as using language to interact with people, we clearly use it to talk about the world, either the external 
world, things, events, qualities, etc., or our internal world, thoughts, beliefs, feelings, etc. As for the processes emphasizing state, the relational and existential processes are included.

\subsubsection{Relational Process}

In Trump's inaugural speech, there are 28 sentences in the relational process, accounting for $28.6 \%$ of the entire speech. It is the process of expressing the attributes and characteristics of things, indicating the process of the relationship between things, and allowing the audience to more clearly understand the information expressed by the speaker. The relational process is generally divided into the process of identifying class relationships and the process of belonging class relationships. Next, the thesis analyzes the clauses in this process and their Chinese translations.

\section{Example 8:}

ST: This is your day. This is your celebration.

TT: 这是你们的日子, 是你们的节庆。

This clause belongs to the identifying relational process. "Your day" and "your celebration" are the Token, while the pronoun "this" is Value. They can change the position with each other. "Is" is the symbol verb of identifying relational process, however, when it is translated in the target text, it is changed into the attributive relational process, because “是” expresses a sense of belonging. Besides, in Chinese version, the elements around the verb cannot change with each other. Sometimes, taking the culture and language of target text into consideration may influence the choice of translation strategy and thus it also influences the result of using which process of transitivity during the process of translation.

In short, Trump established a good image of the new president in front of the audience by using quantification to show the audience the plans, tasks, and commitment to the people after the president's inauguration.

Example 9:

ST: We are one nation - and their pain is our pain. Their dreams are our dreams; and their success will be our success. We share one heart, one home, and one glorious destiny.

$\mathrm{TT}$ : 我们是同一个国家, 他们的痛苦就是我们的痛苦, 他们的梦想就是我们的梦想, 他们的成功就是我 们的成功。我们有着同样的心、同样的家园、同样的伟大命运。

This clause belongs to the relational process. In Trump's speech, using a large number of repetition is one of his major features. By using the four "ones" to describe the people belonging to the same country and uniting as one, the president will share the success and the suffering with people, which can encourage the listeners to convince and support the presidential class. On the one hand, quantitative linguistic potential can strengthen the momentum and determination of Trump's speech, arouse the audience's enthusiasm, and convince them; on the other hand, it can demonstrate the idea of governing the country in Trump's new country that builds solidarity and mutual assistance after its inauguration. In order to create a presidential image that strives for a free, democratic and united nation. The transitivity remains the same when it is translated into the target language. The verb “are" in source text and “是” are both relational process verbs.

Table 5. Relational process analysis

\begin{tabular}{llll}
\hline Participant & Value & Process: Relational & Token \\
\hline ST 1 & This & is & your day; your celebration \\
ST 2 & $\begin{array}{l}\text { We; their pain; } \\
\text { dreams; success }\end{array}$ & are & \\
& & & \\
\hline
\end{tabular}

In Trump's speech, $60 \%$ of the relational process remains the same after translation, while $40 \%$ becomes the material process. The processes of changing transitivity are mostly descriptive processes of environmental relations and process of inclusive relations. This has nothing to do with the form of the language, which is mainly the expression of the meaning of the sentence. If the translation is in accordance with the original text literally and does not change the transitivity of relational process, after the translation, the target text is not in accordance with the Chinese expression habits. Only when the translation is based on the meaning of the faithful original text, can it be translated in accordance with the Chinese customary expression to achieve the desired result. 


\subsubsection{Existential Process}

Existential process is the process of expressing the existence of something. Trump's speech accounts for a very small proportion of the existential process, which basically does not change the transitivity during translation.

Example 10:

ST: At the center of this movement is a crucial conviction: that a nation exists to serve its citizens.

$\mathrm{TT}$ : 这场就职典礼的中心是一个极其重要的信念：国家是为服务人民而存在的！

This sentence belongs to the existential process clause. "Exist" is a symbol verb of existential process and its translated version also belongs to the existential process clause. “是为人民服务而存在的” is correspond to the source text and expresses the function of it.

Example 11:

ST: When you open your heart to patriotism, there is no room for prejudice.

$\mathrm{TT}$ :当你怀着爱国主义的时候，偏见就没有任何空间。

“There is" is an existential sentence and thus it belongs to the existential process. “没有” is the opposite meaning of “要有”, which is a symbol verb of existence. Therefore, the translated version also belongs to the existential process clause.

Table 6. Existential process analysis

\begin{tabular}{lll}
\hline Participant & Process: Existential & Existent \\
\hline ST 1 & exists & a nation \\
ST 2 & is & no room for prejudice \\
\hline
\end{tabular}

In Trump's inaugural speech, all existential process clauses remain unchanged after translation. The existential process is the same as the material process, since their content of the expression is the objective fact. The verbs of the existential process can also find the corresponding words in Chinese. Therefore, in the political speech, the existential clause should be translated into the same transitivity type to maintain the consistency of the physical property.

\section{Conclusion}

Through the analysis of Trump's inaugural speech, we can see that in this speech, the proportion of material processes, relational process, and mental processes are relatively large, accounting for almost $90 \%$ of the entire speech. The proportion of the verbal and existential process is relatively small, in addition, there is no sentence of the behavioral process. It can be concluded that in English political speeches, speakers are better at using material processes and mental processes to state facts or their own ideas. They also use relational processes to explain the relationship between things and make the presentation more logical and systematic. Speakers seldom use verbal processes, existential processes and behavioral processes. Because political speeches are for a certain purpose, there is no need to use many such processes. The first choice in English political speech translation is to be faithful to the structure and semantic expression of the original text, as well as to keep the translation consistent with the original text and the relevant transitivity so that the original text information can be well communicated. In some cases, specific analysis should be carried out according to the specific cases, for instance, sentences that cannot be translated in accordance with the transitivity in original text should be translated on the basis of the semantics and emotions of the original text and translated according to Chinese traditional expressions.

\section{References}

Graber. (2003). Styles of image management during crises: Justifying press censorship. Discourse \& Society, 14(5), 539-557. https://doi.org/10.1177/09579265030145001

Halliday, M. A. K. (2008). An Introduction to Functional Grammar (2nd ed.). Beijing: Foreign Language Teaching and Research Press.

Hu, Z. L., Zhu, Y. S., Zhang, D. L., \& Li, Z. Z. (2017). Introduction to Systemic Functional Linguistics (3rd ed.). Beijing: Beijing University Press.

Huang, Q. (2017). A stylistic analysis of Trump's inaugural speech. Foreign Language Education and Translation Development Innovation Research, 6(4). 
Jiang, Y. C. (2013). Interpreting Han Lide's functional thoughts. Journal of Lanzhou Institute of Education, (2), 49-50.

Li, Y. Z., \& Zou, K. S. (2003). Speech Science. Wuhan: Huazhong University of Science and Technology Press.

Shao, S. Y. (1991). Lectures. Changchun: Northeast Normal University Press.

Thompson. (2008). Introducing Functional Grammar. London Arnold.

$\mathrm{Xu}, \mathrm{Q}$. (2017). The stylistic effects of political speech viewed from the principle of iconicity-Taking Trump as a speech in Washington DC. Beijing: Overseas English, (19), 187-188.

Zhang, H., \& Zhou, D. (2018). Study on the discourse strategy of the image of the American president under the perspective of critical discourse analysis - Based on the inaugural speech of President Donald Trump of the United States. Changchun: Journal of Changchun University of Science and Technology (Social Sciences), $31(1), 124-129$.

Zhang, W. (2010). The equivalent of the translation form under the functional linguistics--Analysis of the transitivity of the English translation of "You Zi". Shanghai: Contemporary Foreign Languages Studies, (5), $18-22$.

\section{Copyrights}

Copyright for this article is retained by the author, with first publication rights granted to the journal.

This is an open-access article distributed under the terms and conditions of the Creative Commons Attribution license (http://creativecommons.org/licenses/by/4.0/). 